\title{
Quantum chemical study on the deacylation step of human chymase
}

Yoshinori Hirano*, Naoki Shinmoto ${ }^{\dagger}$, Masayuki Hata $^{\dagger}$, Minoru Tsuda ${ }^{\dagger}$, and Tyuji Hoshino ${ }^{\dagger, \ddagger}$

${ }^{\dagger}$ Department of Physical Chemistry,

Graduate School of Pharmaceutical Sciences, Chiba University

1-33, Yayoi-cho, Inage-ku, Chiba, 263-8522, JAPAN

‡PRESTO. Japan Science and Technology Agency,

4-1-8 Honcho, Kawaguchi, Saitama, JAPAN

*To whom correspondence should be addressed.

Computational Astrophysics Lab.

The Institute of Physical and Chemical Research (RIKEN)

2-1, Hirosawa, Wako-shi, Saitama, 351-0198, JAPAN

Phone: +81-48-467-9759

Fax: +81-48-467-4078

e-mail: hirano@riken.jp 


\begin{abstract}
Human chymase (HC) is a family of serine proteases and changes angiotensin I (AngI) for angiotensin II (AngII). This production of AngII by $\mathrm{HC}$ is the bypass pathway of renin-angiotensin system and has higher production ability than that. In this study, the deacylation mechanism by human chymase was revealed through quantum chemical calculations. The model reaction system was solved using ab initio MO method with Hartree-Fock level. It was found that $\mathrm{HC}$ had two elementary reactions via tetrahedral intermediate and proton relay did not occur through this deacylation step. Further we compared the structural differences between $\mathrm{HC}$ and acetylcholinesterase, which suggested that the surroundings of catalytic triad decided whether proton relay occurs or not in an enzyme.
\end{abstract}

Keywords: Human Chymase, Mechanism of Human Chymase, Deacylation Mechanism, Serine Protease 


\section{Introduction}

Hypertension is one of the striking factors inducing various lifestyle diseases (arteriosclerosis, brain infarction, cerebral apoplexy, aortic aneurysm, and etc.). Hypertension is thought to be a result from the increase of circulating blood volume and/or the constriction of blood vessels. A treatment of hypertension is to decrease the circulating volume and/or to slack the blood vessels. Angiotensin II (AngII) is one of the factors which constrict blood vessels. Control the concentration of AngII is regarded as an effective treatment for hypertension, because AngII is a vasopressor principle. Reninangiotensin system (RAS) was known for the main production pathway of AngII (Figure 1). Recently, it is reported that the production of AngII in local organs is not only due to the pathway by RAS but also to the bypass pathway by serine proteases (Figure 1) [1]. Human chymase (HC) is a family of serine proteases $[2,3]$. HC has higher ability for production of AngII than RAS $[1,4,5]$. It is considered that AngII produced by HC contributes to the remodeling of blood vessel rather than the regulation of blood circulation. However, the details of $\mathrm{HC}$ is still unclear [6-8]. Clarifying the mechanism of $\mathrm{HC}$ is important, because the development of specific inhibitor for chymase becomes popular [9-12] and the development of effective medicine is expected [5]. HC breaks a peptide bond between Phe8 and His9 which lo- 
cates at the second position from $\mathrm{C}$ terminal of AngI and exchanges AngI for AngII $[13,14]$. This mechanism is a hydrolysis and consists of a sequence of acylation and deacylation steps. Active center of $\mathrm{HC}$ is a catalytic triad which composed of His57, Asp102 and Ser195. It is well known that the configuration of this catalytic triad resembles same kinds of serine protease such as trypsin [15], etc. Therefore, the catalytic mechanism of $\mathrm{HC}$ is assumed to be similar to serine protease's.

There are many reports about the mechanism of peptide hydrolysis by serine protease using experimental and theoretical method [16-21]. In 1969, Blow and co-workers proposed that "Charge-relay theory" [16] (Blow et al., 1969) to explain the activity of Ser residue in catalytic triad during catalytic reaction of chymotrypsin. But Kossiakoff and co-workers indicated that the proton relay did not occur, on a basis of experimental data obtained by neutron diffraction of trypsin with an inhibitor, MonoIsopropylPhosphonyl (MIP) $[19,20]$. In this structure, His residue in catalytic triad has two protons and becomes a positively charged. Cleland, Frey and others proposed "LowBarrier Hydrogen Bond (LBHB) theory" which means that hydrogen atom stays between His and Asp (Glu) (His $\cdots H \cdots A s p(G l u)$ ) when pKa value between proton donor and proton acceptor are same [21]. Accordingly, it seems to be plausible that proton relay does not occur in hydrolysis reaction by serine proteases. But the definite conclusion has not been submitted yet. In this 
study, the reaction process of HC has been examined by performing quantum chemical calculations, and we discuss on the proton relay in the catalysis of serine proteases.

\section{Methods}

To construct a model system, Ser-acylenzyme intermediate was extracted from the X-ray crystallographic structure that is a complex of $\mathrm{HC}$ and substrate inhibitor, succinyl-Ala-Ala-Pro-Phe-chloromethylketone (CMK) (pdbcode: 1PJP) [22]. To construct substrate-enzyme (ES) complex, CMK was replaced with peptide chain of Ile-His-Pro-Phe. This ES complex was placed in rectangular parallelepiped box ( $63 \AA \times 65 \AA \times 61 \AA$ ). 4105 water molecules were generated around $\mathrm{HC}$ and energy minimization was executed using

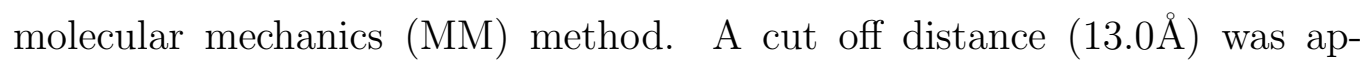
plied for the computation of the van der Waals forces. Energy minimization was performed for a whole system with a periodic boundary condition. In the computation of energy minimization, the steepest descent method was used for the early cycles and the conjugated gradient method was used for the later. The program package used was Insight II/Discover 2000. Next, a model reaction system for quantum chemical (QC) calculations was constructed using the optimized structure from MM calculation. This model 
reaction system contains catalytic triad and its surrounding residues (Figure 2). This structure was fully optimized using QC calculation. Because this structure was based on the X-ray crystallographic structure, we regarded this structure as a standard initial conformation for this study. Astarisked atoms in Figure 2 were fixed through the calculation. Opened circles indicated that carbon atoms were replaced with hydrogen atoms. The model reaction system was solved using ab initio MO method with Hartree-Fock level. The minima and the transition states on the potential energy hypersurface were obtained by geometry optimization using the energy gradient method. Frequency analysis was executed for the optimized structure of the transition state (TS) to check the presence of only one imaginary frequency in the vibrational modes. The steepest descent paths from the TS were calculated for both forward and reverse directions of the vibrational mode corresponding to the imaginary frequency, and the minimum points on both sides of the TS were determined. The above procedure provided the lowest energy reaction path connecting a reactant and a product via TS. The intrinsic reaction coordinate (IRC) calculations were performed to obtain the steepest descent paths for both forward and reverse directions from TS [23]. To re-evaluate the value for potential energy differences, energy calculations were performed with density functional theory (DFT) method including the effect of electron correlation and the second order Møller Plesset perturbation 
(MP2) calculation $[24,25]$ in every stationary point. Becke's three parameter functional [26] incorporating the LYP correlation term $[27,28]$ was used in DFT calculation. The basis set used was $6-31 \mathrm{G}^{* *}[29,30]$. To consider the effects of the inside environment in the protein, we used SCRF (Onsager model) method [31-34] with the condition that dielectric constant of 20.0. This method was already shown to represent the protein environment well [35-38]. The program package used was Gaussian 98 [39].

\section{Results}

\subsection{First elementary reaction: formation of TI}

First step of the deacylation is the formation of tetrahedral intermediate. The transition state of this step (TS1) was determined by approaching oxygen atom of water molecule to carbon atom of inhibitor, I5H. TS1 of this study is shown in Figure 3. This TS1 structure has only one imaginary frequency vibrational mode $\left(681.5875 i \mathrm{~cm}^{-1}\right)$. The arrows in Figure $3(\mathrm{TS} 1)$ show the direction for the vibrational mode corresponding to an imaginary frequency, which indicates the pathway of this reaction. Decomposition of $\mathrm{O}-\mathrm{H}_{\varepsilon}$ bond of water molecule $(1.34 \AA)$ and formations of covalent bonds between oxygen atom of water and carbon atom of $\mathrm{I} 5 \mathrm{H}(2.60 \AA)$ and between $\mathrm{N}_{\varepsilon}$ and $\mathrm{H}_{\varepsilon}(1.14$ 
A) simultaneously occurred.

Next, the steepest descent paths were calculated for the forward and reverse directions of the vibrational mode, and this eventually provided the lowest potential energy path connecting the reactant and the product. As a consequence of calculation for the reverse direction, a stable structure was obtained (Figure 3(initial)). This structure was compared with the standard structure (Figure 2). The potential energies and structural features were resembled each other. It is reasonable to conclude that they are identical. This means that the structure in Figure 3(TS1) is an appropriate TS1 leading from the initial reactant.

The intrinsic reaction coordinate (IRC) calculation [23] was performed for the forward direction following an imaginary vibrational mode of TS1. The potential energy decreased slightly, and tetrahedral intermediate (TI) structure was obtained (Figure3(TI)). Decomposition of $\mathrm{O}-\mathrm{H}_{\varepsilon}$ bond of water molecule $(1.63 \AA)$ and formations of covalent bond between oxygen atom of water and carbon atom of $\mathrm{I} 5 \mathrm{H}(1.50 \AA)$ and $\mathrm{N}_{\varepsilon}-\mathrm{H}_{\varepsilon}(1.04 \AA)$ were completed. 


\subsection{Second elementary reaction: formation of prod- ucts}

Second step of the deacylation is the formation of products. TS2 was determined by approaching $\mathrm{H}_{\varepsilon}$ of water molecule to oxygen atom of Ser195. TS2 of this study is shown in Figure 4. This TS2 structure has only one imaginary frequency vibrational mode $\left(370.0802 i \mathrm{~cm}^{-1}\right)$. The arrows in Figure 4(TS2) show the direction for the vibrational mode corresponding to an imaginary frequency, which indicates the pathway of this reaction. The decompositions of covalent bonds between $\mathrm{N}_{\varepsilon}$ and $\mathrm{H}_{\varepsilon}(1.04 \AA)$ and between oxygen atom of Ser195 and carbon atom of I5H $(1.83 \AA)$ and the bond formation between $\mathrm{H}_{\varepsilon}$ and oxygen atom of Ser195 (1.79 $\left.\AA\right)$ simultaneously occurred.

The IRC calculation was performed for the forward direction following an imaginary vibrational mode of TS2. The potential energy decreased slightly, and a tetrahedral intermediate (TI) structure was obtained (Figure 4(TI)). This structure was compared with TI structure of the first elementary reaction shown in Figure 3(TI). The potential energies and structural features resembled each other. It is reasonable to consider that this structure is identical to TI structure. This means that the structure in Figure 4(TS2) is an appropriate TS2 leading from the first elementary reaction and the initial reactant. 
Following the reverse direction of the vibrational mode, a stable structure was obtained shown in Figure 4(product). In this structure, the decompositions of covalent bonds between $\mathrm{N}_{\varepsilon}$ and $\mathrm{H}_{\varepsilon}(2.31 \AA)$ and between oxygen atom of Ser195 and carbon atom of I5H (2.86 $\AA)$ and the bond formation between $\mathrm{H}_{\varepsilon}$ and oxygen atom of Ser195 (1.05 $\AA$ ) occurred; in other words, this reaction step is the regeneration of serine residue and the production of an acid. This means that this structure is the final product of deacylation step catalyzed by human chymase.

\subsection{IRC calculation}

Figure 5 shows a result of IRC calculation of the deacylation step. It indicates that the deacylation mechanism of human chymase (HC) has two elementary reaction and the activation energy estimated is $45.34 \mathrm{kcal} / \mathrm{mol}$. The energy difference between transition state 1 (TS1) and tetrahedral intermediate (TI) is small $(1.35 \mathrm{kcal} / \mathrm{mol})$. Therefore,TI is an unstable structure. The activation energy required for the second elementary reaction is $5.37 \mathrm{kcal} / \mathrm{mol}$, which was very low compared to the first elementary reaction. The potential energy of the product is slightly higher $(11.44 \mathrm{kcal} / \mathrm{mol})$ than that of the initial one. The activation energy required for this reaction was estimated to be $49.36 \mathrm{kcal} / \mathrm{mol}$ and the rate determing step was the first elementary 
reaction, which formed TI. This reaction is expected to proceed at a body temperature of about $310 \mathrm{~K}$.

\section{Discussion}

\subsection{Deacylation mechanism}

Figure 3 shows the structures of every stationary point in the first elementary reaction. In the initial structure, $\mathrm{H}_{\delta}$ and $\mathrm{N}_{\delta}$ of His57 had a covalent bond and $\mathrm{H}_{\varepsilon}$ was in a part of a water molecule. Compared this structure with the structure shown in Figure 2, it was found that the two structures resembled each other. Therefore, this structure represented a Ser-acylenzyme intermediate, and we accepted this structure as an initial reactant of the deacylation step. In $\mathrm{TS} 1, \mathrm{H}_{\delta}$ remained to be near $\mathrm{N}_{\delta}$ of His57. However, $\mathrm{O}-\mathrm{H}_{\varepsilon}$ bond of water molecule was broken and covalent bond between $\mathrm{H}_{\varepsilon}$ and $\mathrm{N}_{\varepsilon}$ of His57 was generated. In TI, the $\mathrm{H}_{\delta^{-}} \mathrm{N}_{\delta}$ distance remained $1.02 \AA$, and $\mathrm{H}_{\varepsilon}$ was bonded to $\mathrm{N}_{\varepsilon} \cdot \mathrm{H}_{\delta}$ did not move to oxygen atom of Asp102 and remained to be near the $\mathrm{N}_{\delta}$. The charges in imidazole ring changed from neutral to positive $(0.0 \mathrm{e}$ (Initial) $\rightarrow+0.7 \mathrm{e}(\mathrm{TI}))$. Accordingly, tetrahedral intermediate was generated without the transfer of proton from His57 to Asp102 .

Figure 4 shows structures of every stationary point in the second reaction 
step. In TS2(Figure 4(TS2)), $\mathrm{H}_{\delta}$ remained bonded to $\mathrm{N}_{\delta}$ of His57 and the $\mathrm{H}_{\varepsilon}-\mathrm{N}_{\varepsilon}$ distance did not change. However, the covalent bond between oxygen atom of Ser195 and carbonyl carbon atom of substrate (I5H) was broken completely. The imaginary vibrational mode showed that oxygen atom of Ser195 was connected to $\mathrm{H}_{\varepsilon}$ and the orientation of $\mathrm{H}_{\varepsilon}$ changed into oxygen atom of Ser195. In the product, oxygen atom of Ser195 was detached from carbonyl carbon atom of substrate $(\mathrm{I} 5 \mathrm{H})$ and the $\mathrm{H}_{\varepsilon}-\mathrm{N}_{\varepsilon}$ distance was 2.31 A. Acylated Ser195 was recycled and transformed into the initial state, and AngII was produced. After the detachment of AngII, catalytic triad of HC returned to the original conformation and the deacylation was finished. From IRC calculation (Figure 5), it is shown that each stationary point on potential energy hypersurface is connected by two different transition states. We believe that this deacylation mechanism is possible in a living body.

\subsection{Motion of hydrogen atoms}

Deacylation mechanism has two elementary reactions. We focused on the motion of hydrogen atoms $\left(\mathrm{H}_{\varepsilon}\right.$ and $\left.\mathrm{H}_{\delta}\right)$. In the initial state, $\mathrm{H}_{\varepsilon}$ was in a part of the water molecule. As the reaction proceeded, $\mathrm{H}_{\varepsilon}$ moved to Ser195 via His57 from the water molecule. But $\mathrm{H}_{\delta}$ remained to be connected with $\mathrm{N}_{\delta}$ of His57 during this reaction. Therefore, the imidazole ring had two protons in the 
TI state. The result is compatible with neutron diffraction of trypsin which is a family of serine proteases $[19,20]$ and other theoretical researches $[40-$ 47]. These phenomenon indicated that no proton relay occurred during the deacylation of serine proteases. However, other reports suggested that charge relay occurred in the catalysis of other serine proteases [48-53]. Our recent study indicated that the origin of non-proton relay was the strong restraint by the surrounding residues of catalytic triad. Specific configurations decide if proton relay occurs or not through the catalysis [54]. In order to answer whether proton relay occurs or not, the surroundings of catalytic triad was examined for TI of acetylcholinesterase (AChE) and that of $\mathrm{HC}$, and the configurations were compared (Figure 6). In AChE, one carboxyl-oxygen atom (OE1) of Glu327 has two hydrogen bonds with OH of Ser226 and NH of main chain of Asn324, and another carboxyl-oxygen atom(OE2) of Glu327 has a hydrogen bond with $\mathrm{N}_{\delta}$ (Figure $6(\mathrm{a})$ ). It is notable that one hydrogen atom attached to $\mathrm{N}_{\delta}$ of histidine, while another hydrogen atom is connected to oxygen atom of glutamic acid. The structure that had two protons to be bound to the imidazole ring of histidine was never obtained in spite of several trials for optimization using $\mathrm{HF}$ and DFT methods. If two hydrogen atoms were initially attached to the imidazole ring, one hydrogen atom moved to the glutamic acid through the optimization. In contrast, the two protons were bound to the imidazole ring in $\mathrm{HC}$ (Figure 6(b)). In HC, one carboxyl- 
oxygen atom (OD2) of Asp102 has two hydrogen bonds with main chains of Ala56 and His57, and another one (OD1) has two hydrogen bonds with $\mathrm{OH}$ of Ser195 and $\mathrm{N}_{\delta}$ (Figure 6(b)). Accordingly, the small structural differences would decide whether proton relay occurs or not.

\subsection{Potential energy profile}

Potential energy profile (Figure 5) indicated that the required activation energy for the deacylation of $\mathrm{HC}$ was high and TI was not so stable. Hence, we performed energy calculations in every stationary point to re-estimate the potential energy differences using more elaborated method. Zero point vibrational calculations were executed with HF level. The potential energy of TI was slightly higher $(1.11 \mathrm{kcal} / \mathrm{mol})$ than that of TS1 (Table 1$)$. This means that $\mathrm{TI}$ is not the meta-stable state and the reverse reaction ( $\mathrm{TI} \rightarrow$ initial) can occur spontaneously. Next, DFT (B3LYP) calculations including the effect of electron correlation were performed (Table 1). In every stationary point, potential energies obtained by DFT method are lower than those in the HF level. The potential energy of TI was $3.29 \mathrm{kcal} / \mathrm{mol}$ higher than that of TS1. We speculated that the reason why the potential energies between DFT and HF were different was that structures were not optimized by DFT method. To estimate the potential energies more detail, higher or- 
der calculations with MP2 method were performed (Table 1). The potential energies by MP2 are, on the whole, similar to those by HF method. The potential energy of TI was slightly lower $(0.49 \mathrm{kcal} / \mathrm{mol})$ than that of TS1. Consequently, in each case of HF + ZPE, DFT, and MP2, TI was not the stable state and the activation energy for this reaction was still high. Accordingly, it is reasonable to consider that these two elementary reactions occur continuously without the appearance of the tetrahedral intermediate (TI) state. To check the basis set effects for this computational system, additional calculations $(\mathrm{HF} / 6-311++\mathrm{G}(\mathrm{d}, \mathrm{p}))$ were performed at every stationary point (Table 1). The potential energy differences among every stationary point of $\mathrm{HF} / 6-311++\mathrm{G}(\mathrm{d}, \mathrm{p})$ are as same as those of $\mathrm{HF} / 6-31 \mathrm{G}^{* *}$. Therefore, it is confirmed that our results do not depend on the basis set. From the above results, we conclude that TI of this reaction is difficult as an intermediate and a considerably high activation energy needs for this reaction. The requirement of the large activation energy is due to the stability of the Ser-acylenzyme intermediate (the initial state of this study).

Recently, some interesting studies using QM/MM method, which calculate the effects of the inside environment of active center at the molecular mechanics (MM) level, have been reported on the enzymatic reaction mechanism $[43,55]$. Ishida et al. proposed that the activation energy for the acylation mechanism of serine protease was about $20 \mathrm{kcal} / \mathrm{mol}$ [55]. In 
the deacylation mechanism of $\mathrm{HC}$, the activation energy will be reduced if $\mathrm{QM} / \mathrm{MM}$ and/or other methods, that can estimate the effects of the inside environment of the protein accurately, is employed.

\subsection{Influence of surrounding residues of the active site}

In this study, we approximated the environmental influence to the active site using SCRF method $[32,33]$. This method treats the influences as continuum model with a dielectric constant $\varepsilon$. In other proteins, SCRF method was shown to represent the environmental influence well [35-38]. To check the difference of the circumstantial effects between continuum model and real residues, Cys58, Cys42, Tyr94, Lys192, Gly193, Val213, and Tyr215 (residues which located within $6 \AA$ from His57 of $\mathrm{H}_{\delta}$ and $\mathrm{H}_{\varepsilon}$ ) were added to the model reaction system of this study to construct an "extended" model as shown in Fig. 7. The bond distances were set from the MM energy-minimized structure (data not shown). Single point HF and DFT calculations have been executed for the extended models at the initial and TS2 states. The potential energy differences estimated were shown in Table 2. Further, to re-evaluate the environmental influence, additional MP2 calculations were performed using polarized continuum model (PCM) method [56-66] (Table 3). The activation energy, however, was still higher than that calculated for the acylation step 
by Ishida et al. [55] This indicates that two reactions, the acylation and the deacylation, are essentially different in spite of the catalytic reactions in the same enzyme.

In every stationary point, the energy differences between the normal and the extended models were almost same. These results suggest that SCRF method is as effective as the inclusion of actual residues for the purpose of representing the influence of surroundings and that the deacylation mechanism proposed in this study is reasonable.

\section{Conclusions}

Quantum chemical calculations were performed to clarify the catalytic mechanism of chymase, and the following conclusions were provided.

1. The deacylation step of human chymase has two elementary reactions.

2. It would be difficult to detect TI of this reaction, because TI is not stable and the potential energy curve can be approximated by one activation barrier.

\section{zwAcknowledgment}

The authors thank the Research Center for Computational Science, Okazaki. The computations were also carried out by DRIA system at the Gradu- 
ate school of Pharmaceutical Sciences and Institute of Media and Information Technology, Chiba University and by RIKEN Super Combined Cluster (RSCC) System at The Institute of Physical and Chemical Research (RIKEN). This work has been supported by a Grant-in-Aid for Center Of Excellence (COE) research from the Ministry of Education, Science, Sport, and Culture, Japan, by a Special Postdoctoral Research Program for RIKEN (to Y. H.), and by Japan Science and Technology Agency (to T. H.). 


\section{REFERENCES}

[1] H. Okunishi, M. Miyazaki, N. Toda, J. Hypertens. 2, 1984, 227.

[2] H. Urata, A. Kinoshita,K.S. Misono, F.M. Bumpus, A. Husain, J. Biol. Chem. 265, 1990, 22348.

[3] C.F. Reilly, D.A. Tewksbury, N.M. Schechter, J. Travis, J. Biol. Chem. $257, \mathbf{1 9 8 2}, 8619$.

[4] H. Okunishi, Y. Oka, N. Shiota, T. Kawamoto, K. Song, M. Miyazaki, Jpn J. Pharmacol. 62, 1993, 207.

[5] S. Takai, D. Jin, M. Miyazaki, Nippon Yakurigaku Zasshi 114, 1999, 41.

[6] H. Okunishi, Nippon Yakurigaku Zasshi 112, 1998, 203.

[7] M. Miyazaki, T. Wada, N. Shiota, S. Takai, J. Hum. Hypertens. 13, 1999, s21.

[8] M. Miyazaki, N. Shiota, H. Sakonjo, S. Takai, Jpn J. Pharmacol. 79, 1999, 455.

[9] Y. Hayashi, K. Iijima, J. Katada,Y. Kiso, Bioorg. Med. Chem. Lett. 10, 2000, 199.

[10] F. Akahoshi, A. Ashimori, T. Yoshimura, T. Imada, M. Nakajima, N. Mitsutomi, S. Kuwahara, T. Ohtsuka, C. Fukaya, M. Miyazaki, N. Nakamura, Bioorg. Med. Chem. 9, 2001, 301.

[11] U. Neumann, N.M. Schechter, M. Gutschow, Bioorg. Med. Chem. 9, 2001, 947.

[12] M. Sakaguchi, D. Yamamoto, S. Takai, D. Jin, M. Taniguchi, K. Baba, M. Miyazaki, Biochem. Biophys. Res. Commun. 283, 2001, 831.

[13] B.U. Wintroub, N.B. Schechter, G.S. Lazarus, C.E. Kaempfer, L.B. Schwartz, J. Invest. Dermatol. 83, 1984, 336.

[14] D. Yamamoto, N. Shiota, S. Takai, T. Ishida, H. Okunishi, M. Miyazaki, Biochem. Biophys. Res. Commun. 242, 1998, 158.

[15] M.E. McGrath, T. Mirzadegan, B.F. Schmidt, Biochemistry 36, 1997, 14318.

[16] D.M. Blow, J.J. Birktoft, B.S. Hartley, Nature 221, 1969, 337. 
[17] H.C Froede, I.B. Wilson, J. Biol. Chem. 259, 1984, 11010.

[18] C. Viragh, T.K. Harris, P.M. Reddy, M.A. Massiah, A.S. Mildvan, I.M. Kovach, Biochemistry 39, 2000, 16200.

[19] A.A. Kossiakoff, S.A. Spencer, Nature 288, 1980, 414.

[20] A.A. Kossiakoff, Basic Life Sci. 27, 1984, 281.

[21] P.A. Frey, S.A. Whitt, J.B. Tobin, Science 264, 1994, 1927.

[22] P.J. Pereira, Z.M. Wang, H. Rubin, R. Huber, W. Bode, N.M. Schechter, S. Strobl, J. Mol. Biol. 286, 1999, 163.

[23] C. Gonzales, H.B. Schlegel, J. Chem. Phys. 90, 1989, 2154.

[24] C. Møller, M.S. Plesset, Phys. Rev. 46, 1934, 618.

[25] J.A. Pople, R. Seeger, R. Krishnan, Int. J. Quant. Chem. Symp. 11, 1977, 149.

[26] A.D. Becke, J. Chem. Phys. 98, 1993, 5648.

[27] C. Lee, W. Yang, R.G. Parr, Phys. rev. B 37, 1988, 785.

[28] B. Miehlich, A. Savin, H. Stoll, H. Preuss, Chem. Phys. Lett. 157, 1989, 200.

[29] M.M. Francl, W.J. Pietro, W.J. Hehre, J.S. Binkley, M.S. Gordon, D.J. DeFrees, J.A. Pople, J. Chem. Phys. 77, 1982, 3654.

[30] P.C. Hariharan, J.A. Pople, Theoret. Chim. Acta. 28, 1973, 213.

[31] J.B. Foresman, A.E. Frisch, Exploring chemistry with electronic structure methods 2nd edition Chapter 10; Gaussian Inc., 1996, Pittsburgh PA

[32] L. Onsager, J. Am. Chem. Soc. 58, 1936, 1486.

[33] O. Tapia, O. Goscinski, Mol. Phys. 29, 1975, 1653.

[34] M.W. Wong, M.J. Frisch, K.B. Wiberg, J. Am. Chem. Soc. 113, 1991, 4776.

[35] J. Antosiewick, J.A. McCammon, M.K. Gilson, Biochemistry, 35, 1996, 7819 .

[36] Y.Y. Sham, I. Muegge, A. Warshel, Biophys. J. 74, 1998, 1744. 
[37] K. Murata, Y. Fujii, N. Enomoto, M. Hata, T. Hoshino, M. Tsuda, Biophys. J. 79, 2000, 982.

[38] Y. Hirano, M. Hata, T. Hoshino, M. Tsuda, J. Phys. Chem. B 106, 2002,5788 .

[39] M.J. Frisch, G.W. Trucks, H.B. Schlegel, G.E. Scuseria, M.A. Robb, J.R. Cheeseman, V.G. Zakrzewski, J.A. Montgomery Jr, R.E. Stratmann, J.C. Burant, S. Dapprich, J.M. Millam, A.D. Daniels, K.N. Kudin, M.C. Strain, O. Farkas, J. Tomasi, V. Barone, M. Cossi, R. Cammi, B. Mennucci, C. Pomelli, C. Adamo, S. Clifford, J. Ochterski, G.A. Petersson, P.Y. Ayala, Q. Cui, K. Morokuma, D.K. Malick, A.D. Rabuck, K. Raghavachari, J.B. Foresman, J. Cioslowski, J.V. Ortiz, A.G. Baboul, B.B. Stefanov, G. Liu, A. Liashenko, P. Piskorz, I. Komaromi, R. Gomperts, R.L. Martin, D.J. Fox, T. Keith, M.A. AlLaham, C.Y. Peng, A. Nanayakkara, C. Gonzalez, M. Challacombe, P.M.W. Gill, B. Johnson, W. Chen, M.W. Wong, J.L. Andres, C. Gonzalez, M. Head-Gordon, E.S. Replogle, J.A. Pople, Gaussian 98, Revision A.7, Gaussian, Inc., 1998, Pittsburgh PA

[40] A. Warshel, S. Russell, J. Am. Chem. Soc. 108, 1986, 6569.

[41] A. Warshel, G. Naray-Szabo, F. Sussman, J.K. Hwang, Biochemistry $28, \mathbf{1 9 8 9}, 3631$.

[42] A. Warshel, A. Papazyan, Proc. Natl. Acad. Sci. USA 93, 1996, 13665.

[43] J.A. Mulholland, W.G. Richards, PROTEINS 27, 1997, 9.

[44] M. Fuxreiter, A. Warshel, J. Am. Chem. Soc. 120, 1998, 183.

[45] A. Warshel, F. Susmann, J.-K. Hwang, J. Mol. Biol. 201, 1998, 139

[46] M. Topf, P. Várnai C.J. Schifield, W.G. Richards, PROTEINS 47, $2002,357$.

[47] M. Topf, P. Várnai, W.G. Richard, J. Am. Chem. Soc. 124, 2002, 14780.

[48] A.M. Massiah, C. Viragh, M.P. Putta, I.M. Kovach J. Jonson, T.L. Rosenberry, A.S. Mildvan, Biochemistry 40, 2001, 5682.

[49] J. Nishihira, H. Tachikawa, J. theor. Biol. 196, 1999, 513.

[50] S.T. Woldek, J. Antosiewicz, J.M. Briggs, J. Am. Chem. Soc. 119, 1997, 8159. 
[51] P. Masson, L.M. Schopfer, C.F. Bartels, M.-T. Forment, F. Ribes, F. Nachon, O. Lockridge, Biochemca et biophysica Acta. 1594, 2002, 312.

[52] N. Duval, S. Bon, I. Silman, J. Sussman, J. Massoulié, FEBS Lett. 309, 1992, 421.

[53] A. Shafferman, C. Kronman, Y. Flashner, M. Leitner, A. Grosfeld, Y. Ordentlich, Y. Gozes, S. Cohen, N. Ariel, D. Barak, M. Harel, I. Silman, J.L. Sussman, B. Velan, J. Biol. Chem. 267, 1992, 17640.

[54] Y. Hirano, M. Hata, M. Tsuda, T. Hoshino, in preparation.

[55] T. Ishida, S. Kato, J. Am. Chem. Soc. 126, 2004, 7111.

[56] M.J. Frisch, G.W. Trucks, H.B. Schlegel, G.E. Scuseria, M.A. Robb, J.R. Cheeseman, J.A. Montgomery, Jr., T. Vreven, K.N. Kudin, J.C. Burant, J.M. Millam, S.S. Iyengar, J. Tomasi, V. Barone, B. Mennucci, M. Cossi, G. Scalmani, N. Rega, G.A. Petersson, H. Nakatsuji, M. Hada, M. Ehara, K. Toyota, R. Fukuda, J. Hasegawa, M. Ishida, T. Nakajima, Y. Honda, O. Kitao, H. Nakai, M. Klene, X. Li, J.E. Knox, H.P. Hratchian, J.B. Cross, V. Bakken, C. Adamo, J. Jaramillo, R. Gomperts, R.E. Stratmann, O. Yazyev, A.J. Austin, R. Cammi, C. Pomelli, J.W. Ochterski, P.Y. Ayala, K. Morokuma, G.A. Voth, P. Salvador, J.J. Dannenberg, V.G. Zakrzewski, S. Dapprich, A.D. Daniels, M.C. Strain, O. Farkas, D.K. Malick, A.D. Rabuck, K. Raghavachari, J.B. Foresman, J.V. Ortiz, Q. Cui, A.G. Baboul, S. Clifford, J. Cioslowski, B.B. Stefanov, G. Liu, A. Liashenko, P. Piskorz, I. Komaromi, R.L. Martin, D.J. Fox, T. Keith, M.A. Al-Laham, C.Y. Peng, A. Nanayakkara, M. Challacombe, P.M.W. Gill, B. Johnson, W. Chen, M.W. Wong, C. Gonzalez, J.A. Pople, Gaussian 03, Revision C.02, Gaussian, Inc., Wallingford CT, 2004.

[57] S. Miertus, E. Scrocco, J. Tomasi, Chem. Phys. 55, 1981, 117.

[58] S. Miertus, J. Tomasi, Chem. Phys. 65, 1982, 239.

[59] M. Cossi, V. Barone, R. Cammi, J. Tomasi, Chem. Phys. Lett. 225, 1996, 327.

[60] M. Cancès, B. Mennucci, J. Tomasi, J. Chem. Phys. 107, 1997, 3032.

[61] V. Barone, M. Cossi, J. Tomasi, J. Chem. Phys. 107, 1997, 3210.

[62] M. Cossi, V. Barone, B. Mannucci, J. Tomasi, Chem. Phys. Lett. 286, 1998, 253. 
[63] V. Barone, M. Cossi, J. Tomasi, J. Comput. Chem. 19, 1998, 404.

[64] V. Barone, M. Cossi, J. Phys. Chem. A 102, 1998, 1995.

[65] M. Cancès, B. Mennucci, J. Chem. Phys. 109, 1998, 249.

[66] M. Cancès, B. Mennucci, J. Tomasi, Chem. Phys. 109, 1998, 360. 
Table 1: Potential energies in every stationary point.

\begin{tabular}{cccccc}
\hline Method & Initial & TS1 & TI & TS2 & Product \\
\hline HF & 0.00 & 45.34 & 43.99 & 49.36 & 11.44 \\
\hline HF + ZPE & 0.00 & 43.64 & 44.75 & 49.36 & 12.15 \\
\hline \hline B3LYP & 0.00 & 30.03 & 33.32 & 35.87 & 8.83 \\
\hline MP2 & 0.00 & 45.50 & 45.01 & 50.09 & 10.79 \\
\hline HF $/ 6-311++\mathrm{G}(\mathrm{d}, \mathrm{p})$ & 0.00 & 46.79 & 45.57 & 51.35 & 12.99 \\
\hline
\end{tabular}

HF: Potential energy obtained by Hartree-Fock calculations with $6-31 \mathrm{G}^{* *}$. HF + ZPE: Hartree-Fock calculations considering zero point vibration. B3LYP: Density functional theory including the effect of electron correlation through Becke's three parameter functional ${ }^{26}$ incorporating the LYP correlation term ${ }^{27,28}$. MP2: The second order Møller Plesset perturbation calculations. Numerical values are in unit of $\mathrm{kcal} / \mathrm{mol}$. 
Table 2: Potential energy differences between the initial and TS2 states

\begin{tabular}{cccc} 
Model & Method & Initial & TS2 \\
\hline & HF & 0.00 & 49.36 \\
& B3LYP & 0.00 & 35.87 \\
\hline \hline extended & HF & 0.00 & 57.02 \\
& B3LYP & 0.00 & 39.79 \\
\hline
\end{tabular}

Numerical values are in unit of $\mathrm{kcal} / \mathrm{mol}$. 
Table 3: Potential energy differences in every stationary point ('extended' model)

\begin{tabular}{cccccc}
\hline Method & Initial & TS1 & TI & TS2 & Product \\
\hline MP2 (PCM) & 0.00 & 36.55 & 30.86 & 38.86 & 12.09 \\
\hline
\end{tabular}

MP2 (PCM): Potential energy obtained by MP2 calculations using the polarized continuum model (PCM) method with $6-31 \mathrm{G}^{* *}$ basis set under the condition that dielectric constant of 20.00. Numerical values are in unit of $\mathrm{kcal} / \mathrm{mol}$. 


\section{Captions for Illustrations}

Fig. 1: Flowchart of Renin-Angiotensin System (RAS). RAS is known as the main production pathway of angiotensin I (AngI) from angiotensinogen. Human chymase (chymase) also changes AngI for angiotensin II (AngII) in local organs, which is a bypass reaction of AngI $\rightarrow$ AngII conversion. When AngII is bound to AT1 receptor, several very important functions are induced.

Fig. 2: Standard initial structure. This structure was based on the X-ray crystallographic structure (pdbcode: 1PJP) [22]. Astarisked atoms were fixed during the calculation. Opened circles indicate that carbon atoms were replaced with hydrogen atoms.

Fig. 3: Structures of the stationary points on the first elementary reaction. (initial): Stable structure at the last point of the steepest descent path for the reverse direction of the vibrational mode of TS1. This structure is considered identical to that of Figure 2. (TS1): Optimized structure for the transition state in the first elementary reaction. The arrows indicate the direction of the vibrational mode. (TI): Stable structure obtained at the last point of the steepest descent path for the forward direction of TS1. Covalent bonds between $\mathrm{N}_{\varepsilon}$ and $\mathrm{H}_{\varepsilon}$ and between oxygen atom of a water and carbon atom of $\mathrm{I} 5 \mathrm{H}$ are generated. 
Fig. 4: Structures of the stationary points on the second elementary reaction. (TI): Tetrahedral intermediate structure obtained from TS2. (TS2): Optimized structure for the transition state in the first elementary reaction. The arrows indicate the direction of the vibrational mode. (product): Optimized structure obtained at the last point of the steepest descent path for the forward direction of TS2. Regeneration of the active serin residue and production of an acetic acid were confirmed. This means that this structure is a final product of the deacylation step catalyzed by human chymase.

Fig. 5: Potential energy profile in the deacylation reaction catalyzed by human chymase. The abscissa and the ordinate represent the distance of reaction coordinate $\left(\mathrm{amu}^{1 / 2} \AA\right)$ and the potential energy $(\mathrm{kcal} / \mathrm{mol})$, respectively.

Fig. 6: Structural difference between acetylcholinesterase and human chymase. (a) TI structure of acetylcholinesterase obtained by ab initio MO calculation. (b) TI structure of HC.

Fig. 7: Extended model structure for human chymase. Cys58, Cys42, Tyr94, Lys192, Gly193, Val213 and Tyr215 residues are added to the model reaction system shown in Fig. 2 . 


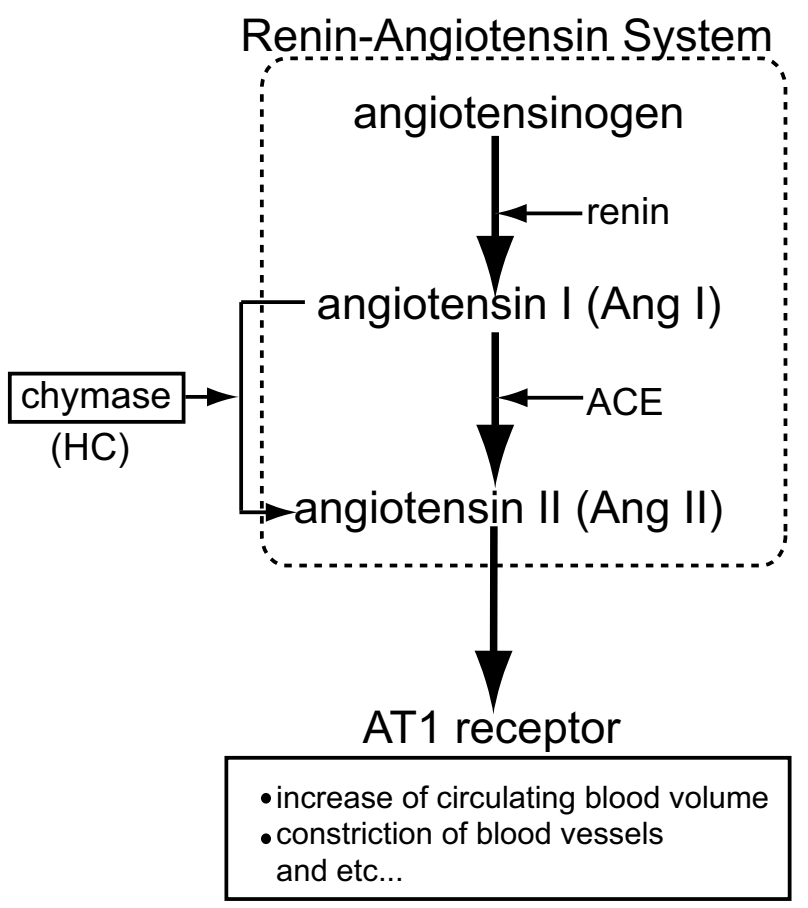

Fig. 1: 


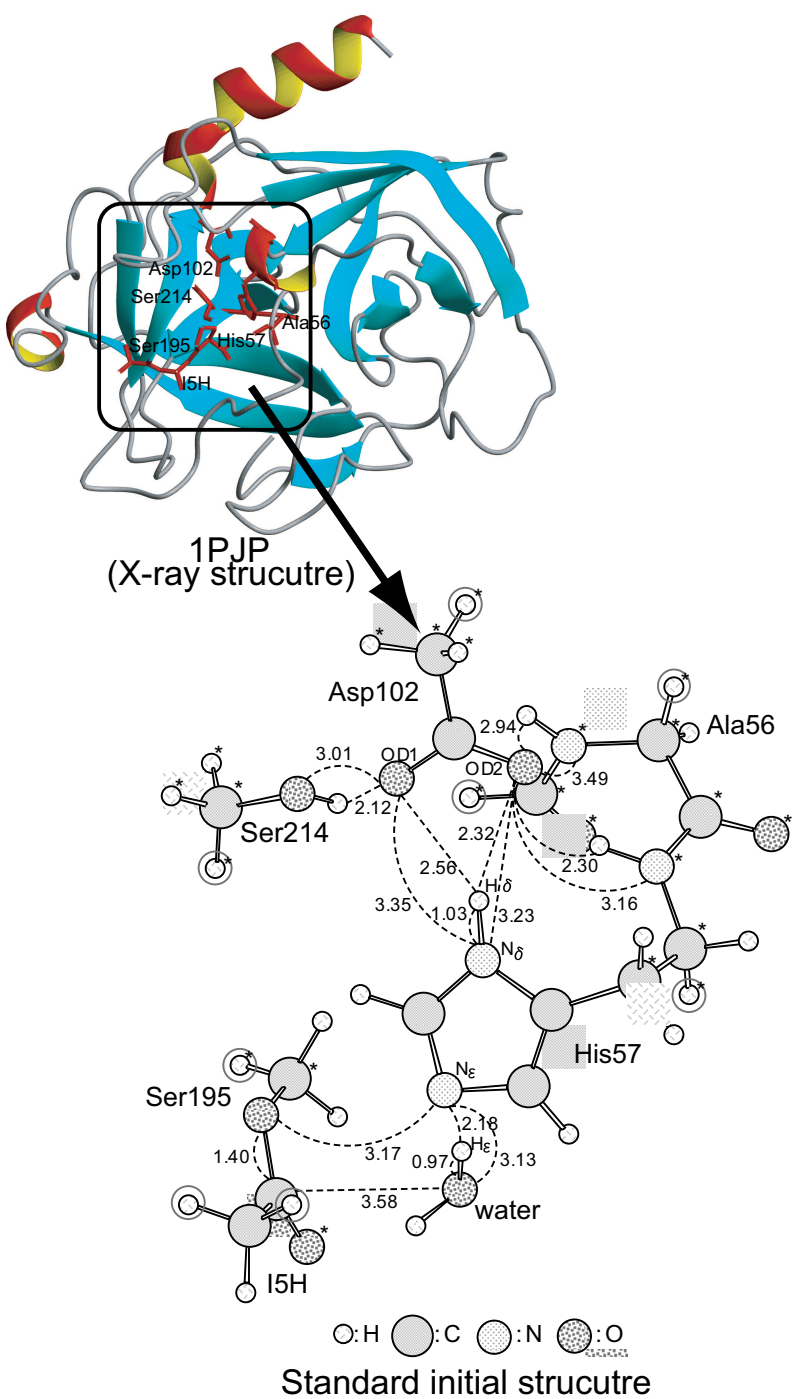

Fig. 2: 

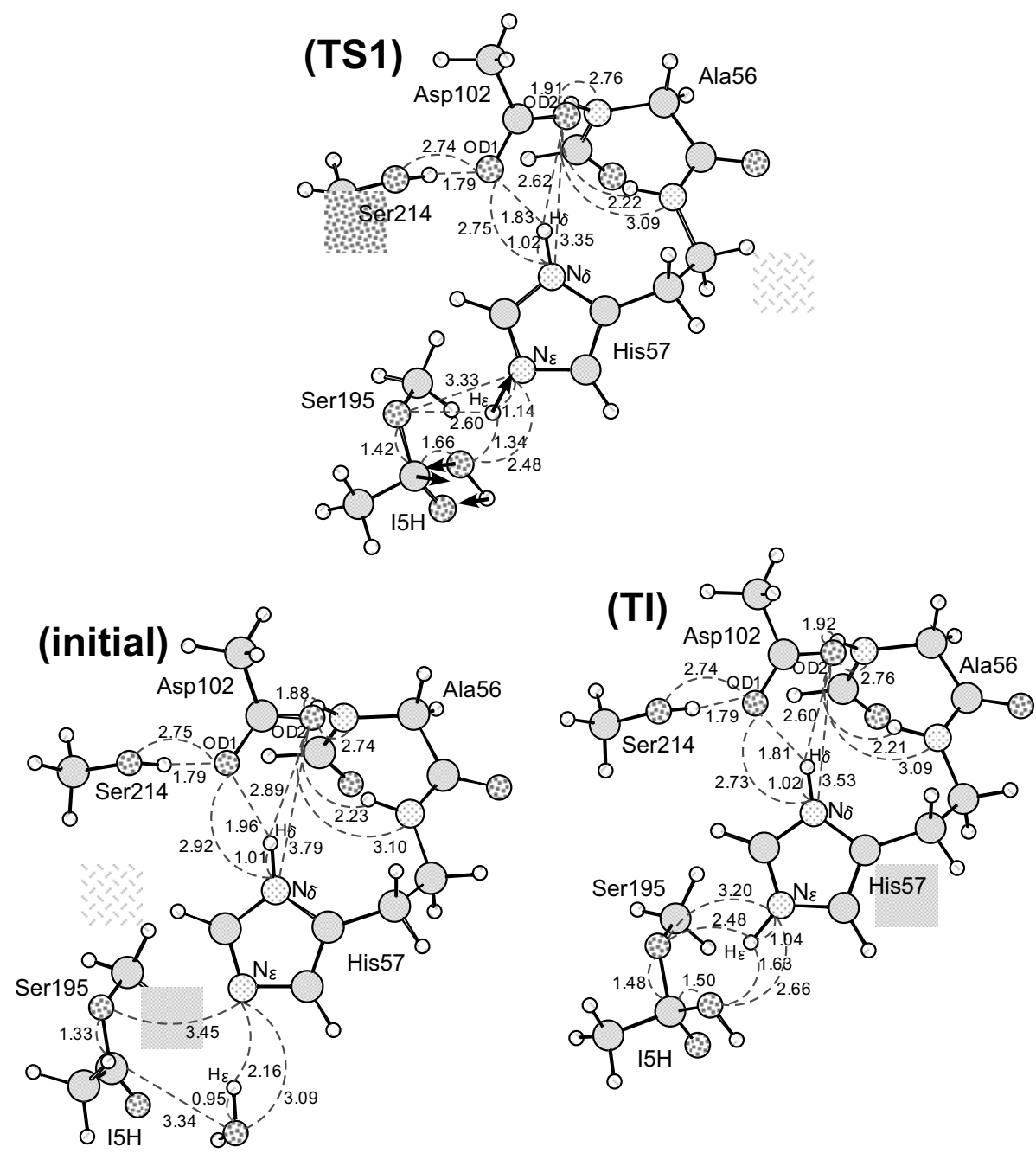

Fig. 3: 

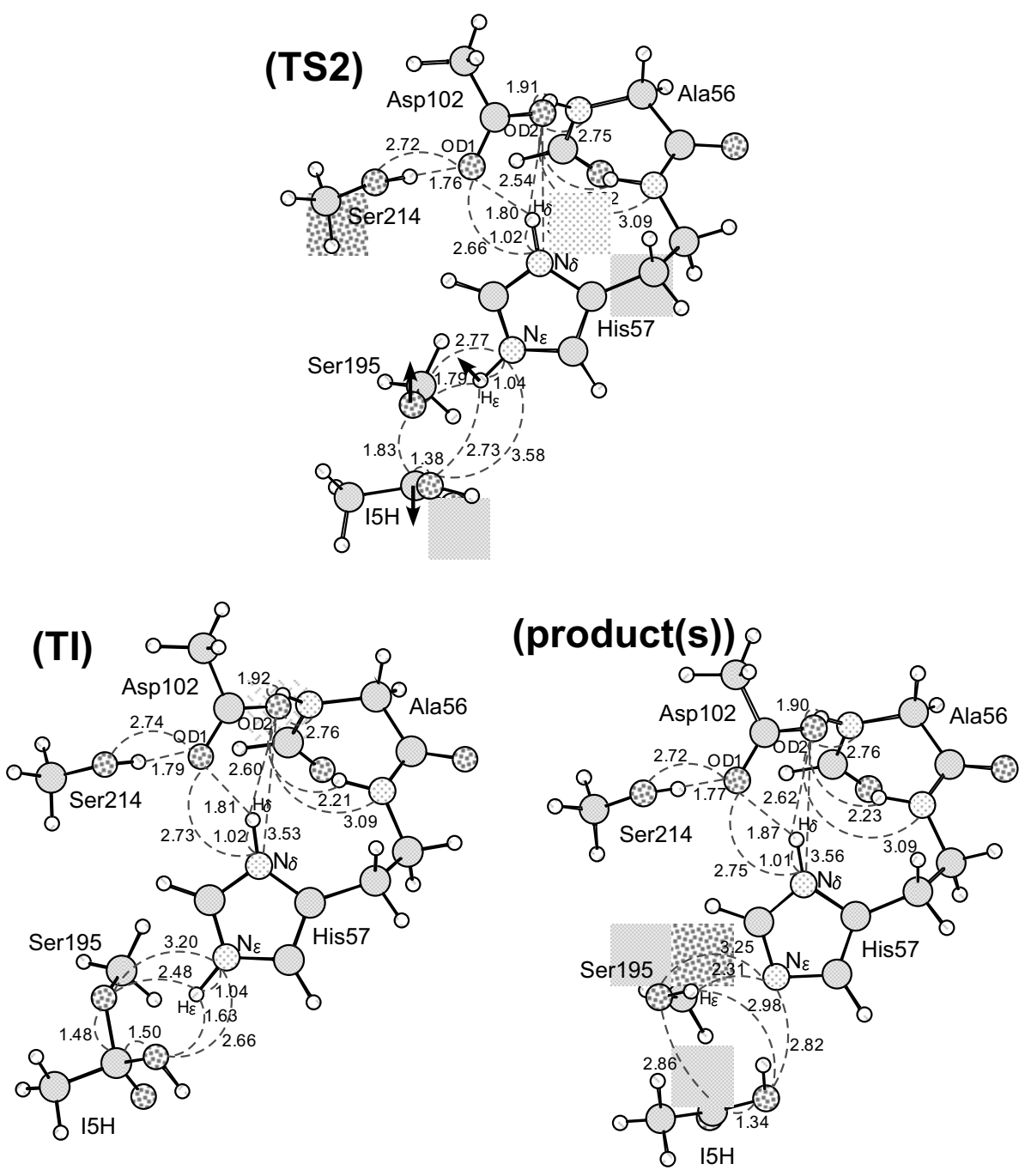

Fig. 4: 


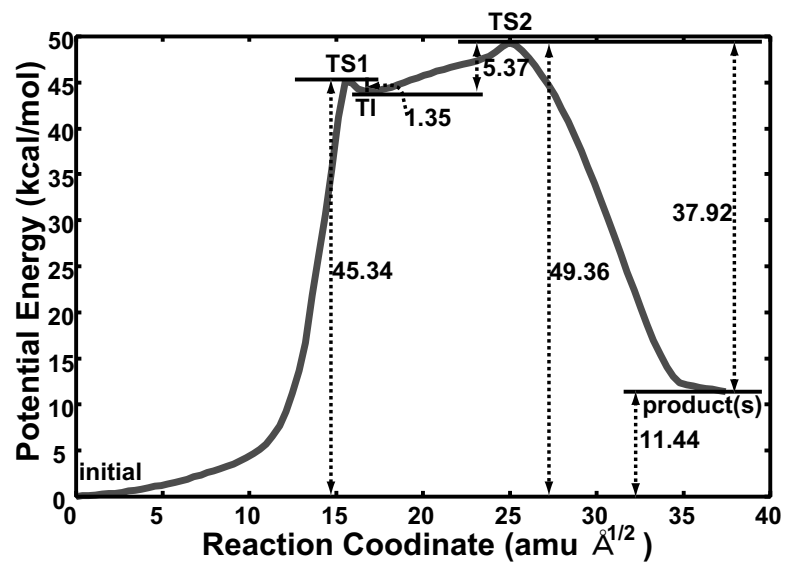

Fig. 5: 

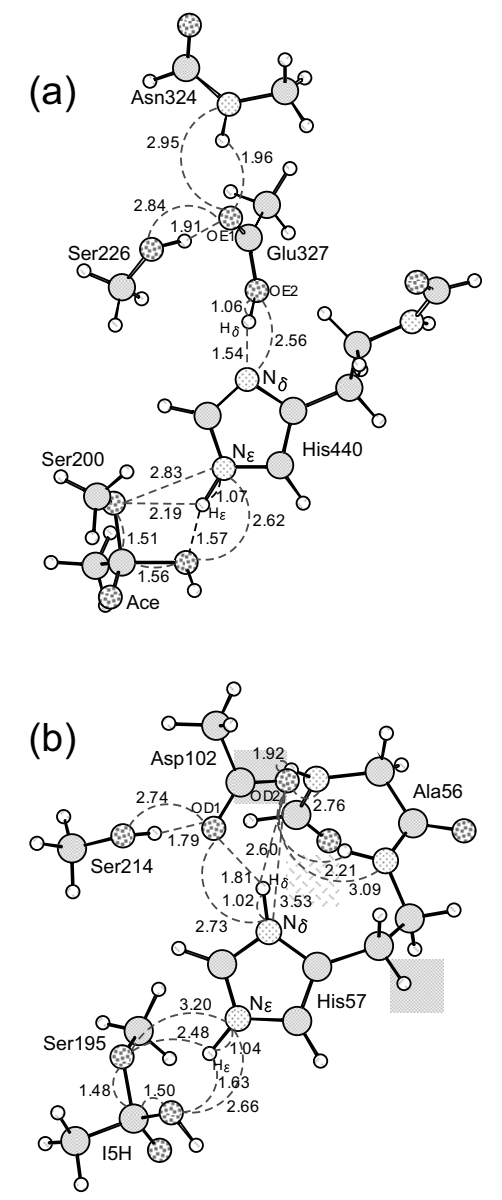

Fig. 6: 


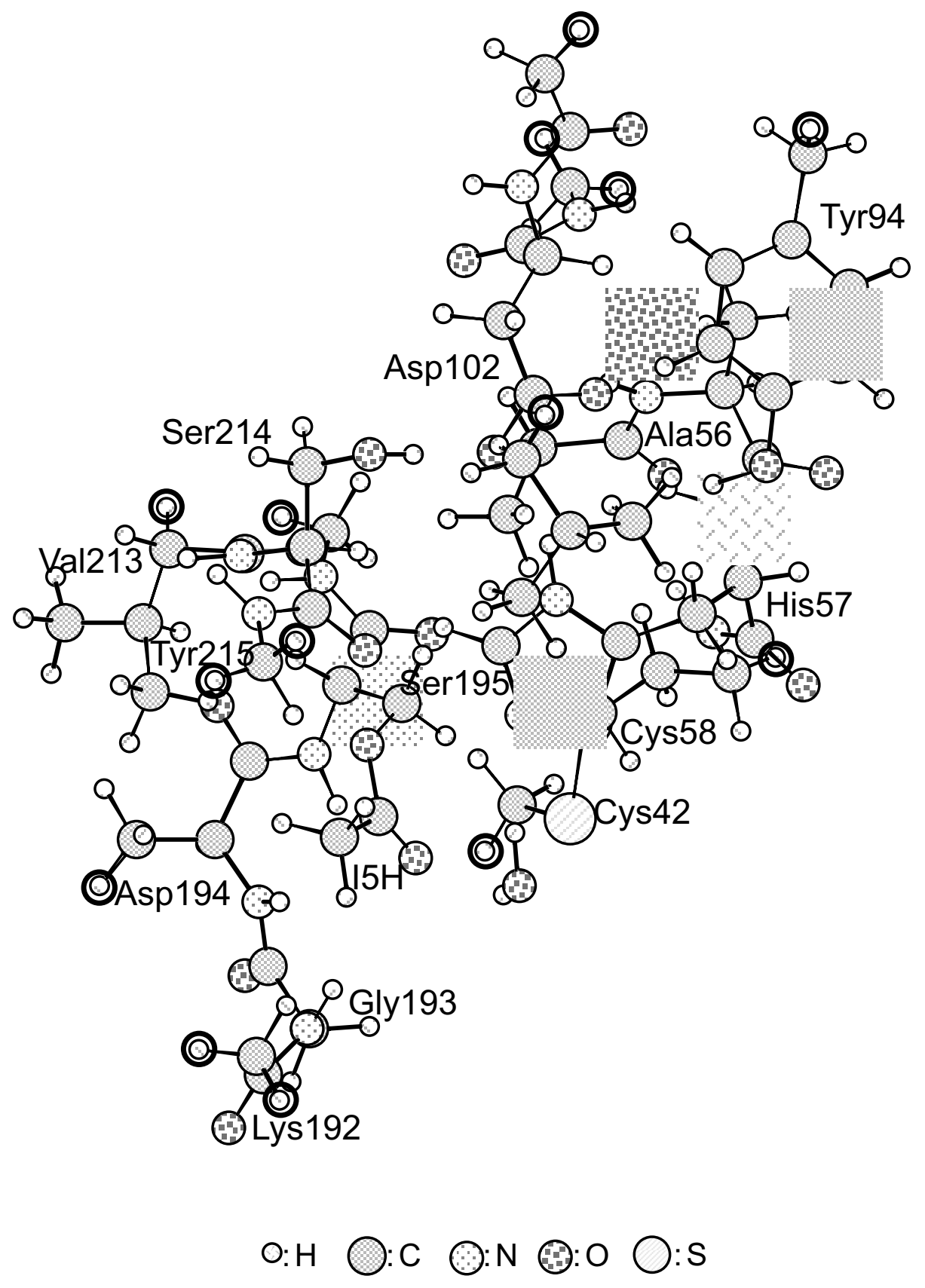

Fig. 7:

35 